\title{
Mikrouhinen bidezko beroketaren onurak koloratzailez dopaturiko material hibridoen sintesian
}

\author{
(Benefits of the microwave oven towards the synthesis of doped \\ hybrid materials)
}

\author{
Ainhoa Oliden-Sánchez*, Rebeca Sola-Llano \\ Euskal Herriko Unibertsitatea (UPV/EHU)
}

\begin{abstract}
LABURPENA: Teknologiak izan dituen aurrerapauso ikaragarriak direla eta, gero eta propietate konplexuagoak dituzten sistemak behar dira gaur egungo beharrak asetzeko, eta, maiz, ezaugarri horiek nekez lor daitezke ohiko materialekin. Arazo horri aurre egiteko, ezaugarri berri eta hobetuak erakusten dituzten material hibridoek indar handia hartu dute. Horren harian, molekula organiko fotoaktiboak barnean hartzen dituzten euskarri ez-organikoak interesgarriak dira, molekula organikoei zurruntasuna, babesa eta ordena eskaintzen dizkietelako, kromoforoen propietateak sendotuz. Lan honetan, berebiziko interesa duen eta infragorri hurbileko eremuan erradiazio elektromagnetikoa igortzen duen material baten garapena deskribatzen da: MgAPO-5 material zeolitikoan kapsulatutako LDS 730 hemizianina, hain zuzen. Aplikazio teknologikoak gogoan izanda, propietate fotofisikoak eta estrukturalak aztertzeaz gain, sintesi-prozesua ere ikertu da, eta materiala bi beroketa-metodoren bidez lortu. Horrela, ohiko labearen eta mikrouhin-labearen bidezko sintesiak konparatu dira, eta azken honen abantailak goraipatu.
\end{abstract}

HITZ GAKOAK: material hibrido fotoaktiboa, infragorri hurbileko igorpena, mikrouhinen bidezko sintesia.

\begin{abstract}
Due to the huge steps forward the technology has undergone, more and more sophisticated properties are required in systems to accomplish today's needs, and often these features can hardly be achieved with conventional materials. In order to tackle this problem, hybrid materials have entered with great force, which can have new and improved features. Hence, inorganic supports that include photoactive organic molecules are very interesting, because they provide rigidity, protection and order to organic molecules, reinforcing the properties of chromophores. This paper describes the development of LDS 730 hemicyanine embedded in MgAPO-5 zeolite, an outstanding material that emits electromagnetic radiation in the near infrared region. In addition to outlining technological applications, the photophysical and structural properties of this material have been analyzed together with two types of heating synthesis processes: the conventional and microwave oven-synthesis have been compared, highlighting the advantages of the last one.
\end{abstract}

KEYWORDS: hybrid photoactive material, NIR emission, microwave synthesis.

\footnotetext{
* Harremanetan jartzeko / Corresponding author: Ainhoa Oliden-Sánchez, Kimika Fisika saila, Euskal Herriko Unibertsitatea, UPV/EHU, PK, 644, 48080, Bilbo, Euskal Herria. - ainhoa.oliden@ehu.eus - https://orcid.org/0000-0003-1734-3731.

Nola aipatu / How to cite: Oliden-Sánchez, Ainhoa; Sola-Llano, Rebeca (2020). «Mikrouhinen bidezko beroketaren onurak koloratzailez dopaturiko material hibridoen sintesian»; Ekaia, 37, 2020, 117-128. (https://doi.org/10.1387/ekaia.20858).

Jasoa: 15 maiatza, 2019; Onartua: 13 azaroa, 2019.

ISSN 0214-9001 - eISSN 2444-3255 / (c) 2020 UPV/EHU
}

(c) (-) Obra hau Creative Commons Atribución 4.0 Internacional-en

lizentziapean dago 


\section{SARRERA}

Prozesu eta erreakzio kimikoen erraztasun eta sinpletasunaren peskizan ibili ohi gara zientzialariok. Bilaketa-prozesu horretan hainbat eta hainbat baldintza hartzen dira kontuan, besteak beste, gaur egun ezaguna den Green Chemistry delakoa, edota ahalik eta eraginkortasun eta etekin handienaren lorpena. Horixe da, funtsean, lan honen xedea: zehazki, sintesi hidrotermalen (disoluzio akuosoen kristalizazioa tenperatura eta lurrun presio altuetan) denbora gutxitzea, ahalik eta errendimendu handiena lortuz koloratzailez dopaturiko material hibridoen sintesian.

Material hibrido horiek orain arte honenbeste arlotan agerian utzi duten potentzialagatik aukeratu dira. Materialen kimikan sekulako aurkikuntza eragin dute (argitalpenetan, gorakada esponentziala sumatu da azkeneko urteotan). Honela, propietate desberdineko konposatu organikoen eta ezorganikoen arteko konbinaketa eginez, are eta ezaugarri onuragarriagoak lor daitezke efektu sinergikoengatik, indibidualki bakoitzak izan ditzakeen propietateak gehituz baino [1, 2]. Horregatik, material horiek hainbat arlotan aplika daitezke, besteak beste, optikan, elektronikan, mekanikan, energian, etab [1-6].

Lan honetan aztertuko diren material hibridoak koloratzaileak kapsulatuta dituzten matrize ez-organiko porotsuetan oinarritzen dira. Egitura ezorganiko horiek zeolitikoak dira, konkretuki aluminofosfato (AlPO) izenekoak, eta erabilitako koloratzaile organikoa egitura horien propio den nanokanaletan txertatuko da; honela, material solido hibrido berria garatuko da aplikazio optikoetarako. Aipaturiko azpiegitura ez-organiko horiek neutroak dira, $\mathrm{AlO}_{4}$-aren eta $\mathrm{PO}_{4}$-aren arteko ordezkapenengatk, eta 4-12 Å arteko nanokanalak dituzte [7]. Bestalde, tarteka aluminofosfato egiturek karga edukitzea nahitaezkoa da, koloratzaile kationikoen barneraketa bultzatzeko. Hori dela eta, ikerketa honetan, Mg (II) katioi dibalentea dopatzaile gisa erabili da aluminofosfatoari karga negatiboa sustatzeko nanokanalen barnean. $\mathrm{Mg}^{2+}$ katioi horrek koordinazio tetraedrikoa har dezakeenez, $\mathrm{Al}^{3+}$ atomoak magnesioarekin ordezkatuko dira egiturako zenbait tokitan; azkeneko egituran ez da asaldurarik eragingo, baina Bronsted azido-guneak sortuko dira (1. irudia). Lortutako materialari magnesio aluminofosfato edo $\mathrm{MgAPO}$ deritzo[8].

(V)

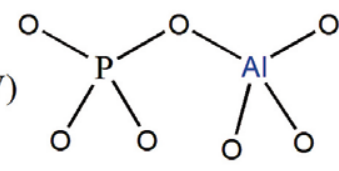

(III)

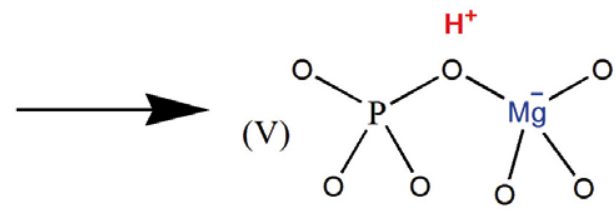

1. irudia. Mg hetereoatomoak AIPO egituran duen ordezkapenaren irudikapen eskematikoa MgAPO egitura sortzeko. 
Orokorrean, material horiek molekula fotoaktibo batekin konbinatzean, ostalari organikoaren propietate kimiko eta fisikoen hobekuntza bat lortzen da, egonkortasun termiko eta fotonikoaren gorakadarekin batera. Molekulen tamainen antzeko diametroak dituzten 1D-nanokanalak hartzaile apartatzat jotzen dira molekula fotoaktiboen antolaketa supramolekularra lortzeko [9]. Horrela, fluoreszentzia altuko eta ordena handiko sistemak garatu daitezke tresna edo gailu berrien diseinurako.

Helburu horretarako, espektro elektromagnetikoaren alde gorrian fluoreszentzia igortzen duen hemizianina motatako koloratzaile bat aukeratu da, LDS 730 izenekoa (2. irudia). Fluoreszentzia substantzia batzuek irrada bat jasotzean argia igortzeko duten gaitasuna da. Orokorrean, hemizianina motako kromoforoak aromatikoak dira eta haien egitura molekularrean talde elektroi-emaile eta -hartzaile bat daukate. Gure koloratzailearen kasuan, egituran anilina bat (amina primarioa, bentzenotik eratorria) eta pirrol talde bat (bost katen mailako konposatu heteroziklikoa, $\mathrm{C}_{4} \mathrm{H}_{5} \mathrm{~N}$ ) ageri dira; lehenengoak elektroi-emaile gisa jokatzen du, eta azkenak (karga positiboduna), berriz, elektroi-hartzaile gisa (2. irudia).
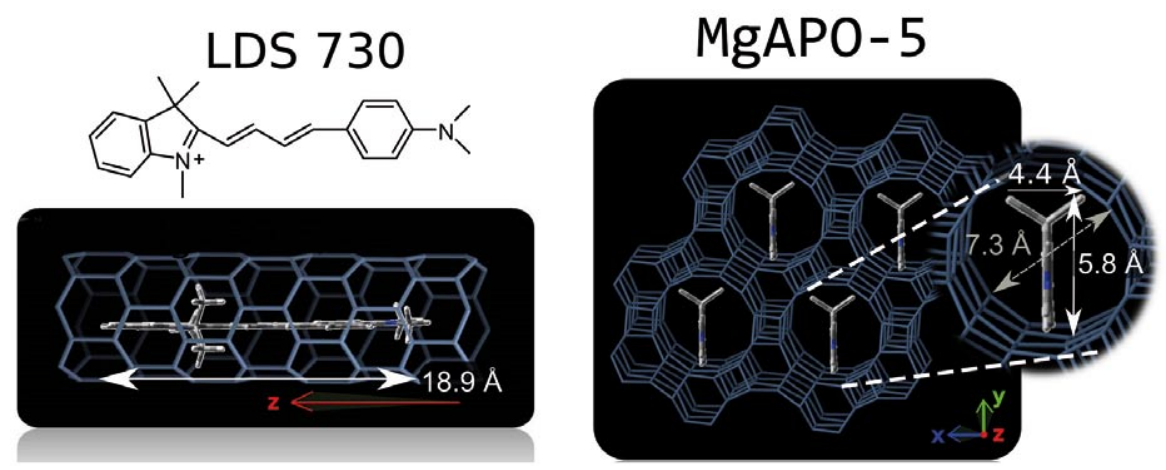

2. irudia. LDS 730-ren egitura molekularra, haren dimentsioak eta egokitzapen estua MgAPO-5 (AFI fasea) egituran.

Mugikortasun handia duten molekula horiek (egituraren kate konjugatua dela eta) normalean oso baxuak diren etekin kuantiko fluoreszenteak dituzte, disoluzioan beren loturen inguruan jasaten dituzten mugimendu errotazionalak direla eta [10]. Era horretan, mugikortasun hori saihesteko koloratzaile hauen konfinamendu zurruna ezartzea da giltza. Zeolita ostalariaren poroen irekierak koloratzailea estu harrapa dezan, hainbat aluminofosfato-egituratatik MgAPO-5 egitura aukeratu da (laburdura-kodea erabiliz AFI deritzona eta $5,8 \AA \times 17,8 \AA \times 4,36 \AA$ dimentsioak dituena; 2 . irudia).

LDS 730 hemizianinaren txertaketa «cristalization inclusion» metodoaren bidez egin da. Metodo horretan, koloratzailea sintesi-nahastera zuzenean 
gehitzen da, eta haren barneraketa «in situ» lortzen da; hau da, kromoforoa egitura ez-organikoaren nanokanaletan harrapatuta gelditzen da matrizea kristalizatu heinean, eta sintesi osteko txertaketa-prozesuak saihesten dira. Beroketa-iturri gisa bi metodo aplikatu dira: ohiko labea eta mikrouhin-labeak. Ikerketek iradokitzen dutenez, azken honek sintesi-denbora magnitude-ordena batez murriztu dezake [12], eta sintesi-gelak berehala nahi den tenperaturara berotzea ahalbidetzen du. Abantaila horiek materialaren etengabeko ekoizpena ahalbidetzen dute aplikazio kimikoetarako, batez besteko kostua murrizten baita (denbora eta energia aurrezten da). Are gehiago, mikrouhin-labeetan egindako sintesiak labe konbentzionaletan egindakoak baino produktu homogeneoagoak sortzen dituela frogatu izan da (ikus 3. irudian abantailak) [13]. Hortaz, ikerketa honetan, koloratzailez dopaturiko aluminofosfatoen sintesia hobetu daitekeela egiaztatuko da, mikrouhinn-labearen eta labe konbentzionalaren arteko erkaketa eginez.

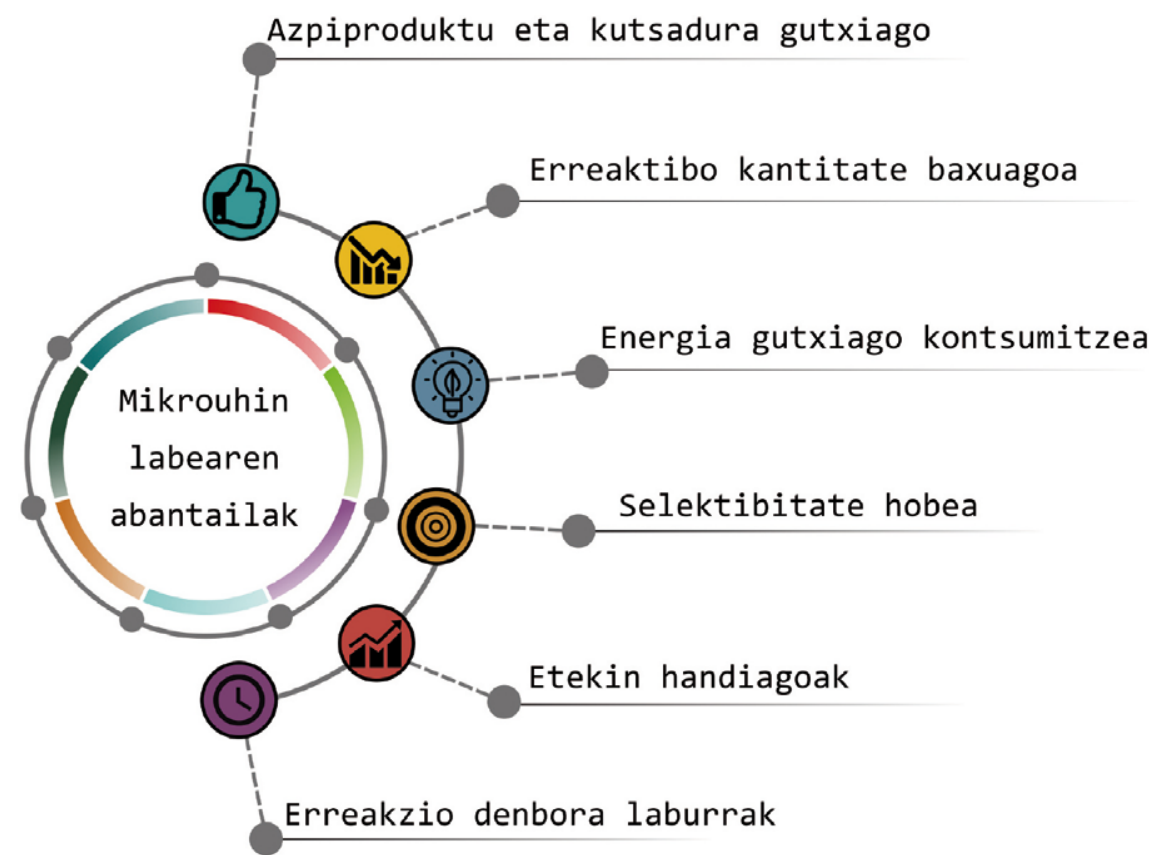

3. irudia. Mikrouhin-labeak aplikatzearen zenbait abantaila labe konbentzionalarekiko.

\section{MATERIAL HIBRIDOEN SINTESIA}

LDS 730 (2-[4-(4-Dimetilaminofenil)-1,3-butadienil]-1,3,3-trimetil$3 \mathrm{H}$-indolio perkloratoa) koloratzailez dopaturiko MgAPO-5 material hi- 
bridoak sintesi hidrotermalaren bidez sintetizatu dira mikrouhin-labea zein ohiko labea erabiliz. Sintesi hidrotermala konposatu eta material kimiko ezberdinak ekoizteko metodo bat da; horretan, sistema itxian, eta prozesu fisiko-kimikoak erabiliz, disoluzio urtsu bati $100^{\circ} \mathrm{C}$-tik gorako tenperatura eta $1 \mathrm{~atm}$ baino gehiagoko presioa aplikatzen zaizkio altzairu herdoilgaitzezko autoklabe batean. Hortaz, 0,1 $\mathrm{MgO}: 1 \mathrm{P}_{2} \mathrm{O}_{5}: 0,95 \mathrm{Al}_{2} \mathrm{O}_{3}: 1$ TEA: 0,024 LDS 730: $305 \mathrm{H}_{2} \mathrm{O}$ konposiziodun gela prestatu da, aldez aurretik beste koloratzaile batzuekin lortutako emaitza egokiengatik [9], eta magnesio aluminofosfato mikroporoso horiek egiteko, azido fosforikoa, magnesio azetato tetrahidratatua, aluminio hidroxidoa, trietilamina eta LDS 730 koloratzailea erabili dira.

Koloratzailea ingurunean nahasgarria izan dadin, gel urtsuak prestatu dira $\left(305 \mathrm{H}_{2} \mathrm{O}\right.$; ikus gelaren konposizioa). Lehenbizi, azido fosforikoa uretan nahasi da propilenozko prezipitatu-ontzi batean, eta 2 minutu inguru irabiatzen laga da. Ondoren, aluminio hidroxidoa aluminio-iturri gisa gehitzen da, eta lortutako nahastea ordubetez irabiatzen utzi da. Magnesio azetato tetrahidratatua gehitu da magnesio-iturri gisa, eta beste ordu erdiz utzi da. Azkenik, egitura zuzenduko duen trietilamina gehitu zaio koloratzailearekin batera, eta ordubetez mantendu da.

Aurretik azaldutako prozedura dela bide, konposizio bereko bi gel prestatu dira; horietako bat ohiko labean, eta bestea, berriz, mikrouhin-labean. Gelen pH-balioak 3 eta 5 ingurukoak izan dira. Ur-nahastea tefloizko autoklabera sartu eta estatikoki berotu da ETHOS Advanced Microwave Digestion system (Millestone) izeneko mikrouhin-labean $160^{\circ} \mathrm{C}$-an, $500 \mathrm{~W}$-ean, 2 orduz, edota Venticell labe konbentzionalean, 24 orduz. Produktu solidoak iragazpenaren bidez berreskuratu dira, etanolez eta urez sakonki garbituz, eta inguru-tenperaturan lehortzen utzi dira (ikus prozedura 4. irudian).

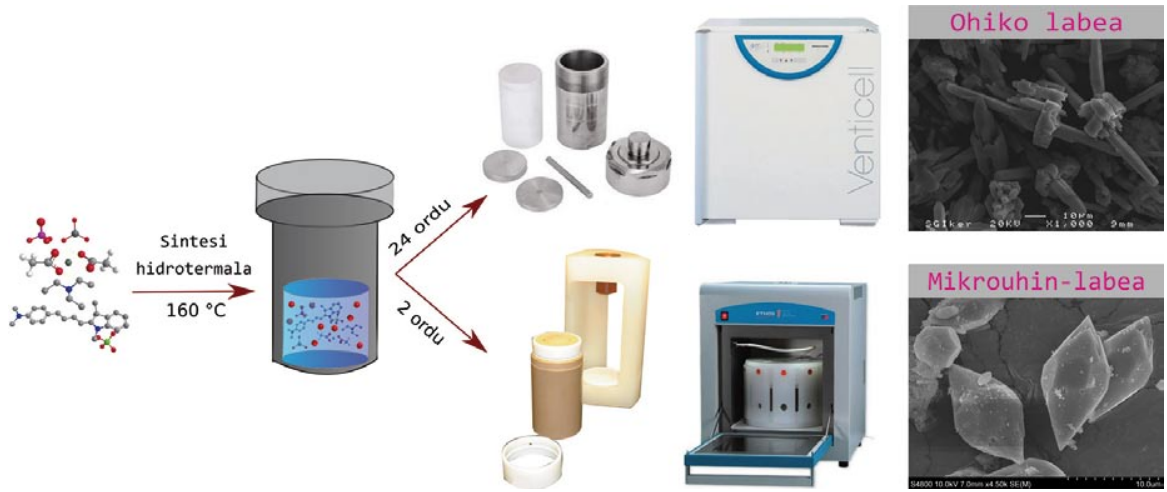

4. irudia. Dopaturiko magnesio aluminofosfatoen sintesi hidrotermalaren prozeduraren eskema. 
Amaierako materialen propietate fotofisikoak aztertzeko, teknika espektroskopikoak erabili dira (absortzio- eta igorpen-espektroskopiak), eta materialen itxura eta morfologia zein propietate optikoak aztertzeko, berriz, mikroskopio optikoa eta ekorketako mikroskopio elektronikoa.

\section{EMAITZAK ETA EZTABAIDA}

0,1 MgO: $1 \mathrm{P}_{2} \mathrm{O}_{5}$ : 0,95 $\mathrm{Al}_{2} \mathrm{O}_{3}$ : 1 TEA: 0,024 LDS 730: 305 gel-konposizioa duten A eta $\mathrm{B}$ laginei (ikus 1 . taula) $160^{\circ} \mathrm{C}$-ko tenperatura aplikatu zaie, LDS 730-ren degradazio-tenperatura ez gainditzeko asmoz $\left(\approx 260{ }^{\circ} \mathrm{C}\right)$. Tenperatura hori analisi termograbimetriko baten bidez kalkulatu da. Analisi horretan, laginaren masa denboran zehar neurtu da tenperatura aldatuz, eta, horrela, degradazio-tenperatura determinatu ahal izan da, lortutako kurbaren deribatua eginez (5a. irudia). Neurketa horiek baldintza orokorretan egin dira, autoklabe barruan jasaten den presioa kontuan izan gabe. Izatez, lortutako degradazio-tenperaturari erreparatuz, badirudi esperimentalki aplikatu dena baino tenperatura altuagoak aplika daitezkeela. Aitzitik, sintesi hidrotermalaren presio altua izanik, berezko degradazio-tenperatura baxuagoa izango da (beste koloratzaile batzuekin balioztatuta) [14]; hori dela eta, $160{ }^{\circ} \mathrm{C}$-an sintetizatzea hautatu da. Bestalde, sintesi-gela ohiko labean 24 orduz berotzen laga da, eta mikrouhin-labean, ordea, 2 orduz.

1. taula. Sintetizatutako laginen itxura, aplikatutako bero-iturria eta lortutako ezaugarri fotofisikoak, xurgapeneko $\left(\lambda_{\text {xur }}\right)$ zein igorpeneko $\left(\lambda_{\text {ig }}\right)$ uhin-luzerak adierazten direlarik.

\begin{tabular}{|c|c|c|c|c|}
\hline Lagina & Itxura & Bero-iturria & $\lambda_{\text {xur }}(\mathrm{nm})$ & $\lambda_{\text {ig }}(\mathrm{nm})$ \\
\hline A & & labea & 698,5 & 847 \\
\hline B & & mikrouhinak & 695,0 & 814 \\
\hline
\end{tabular}

Lortutako material hibridoen X izpien difrakzioan AFI fase purua lortu dela beha daiteke bi kasuetarako, fasearen bereizgarria den pikua agertuz guztietan $\left(7,58^{\circ} ; 5\right.$ b. irudia) [15]. Begi-bistakoa da AFI egitura termodinamikoki faboratuta dagoela, tenperatura oso altuak aplikatu gabe fasearen lorpena berehalakoa baita, eta horrez gain, kristalinitate altuko materiala 
lortzen baita. Difraktograman, aldiz, A materialaren kristalinitate-maila altuagoa ageri da, gailurren intentsitate altuagoek adierazten duten moduan. Beraz, AFI fasea duen MgAPO-5 materiala lortu da bi sintesi-bideei jarraituz. Hortaz, hemendik aurrera koloratzailez dopaturiko material horri erreferentzia egiteko asmoz, sintesi-bidea edozein izanda ere, LDS 730/AFI nomenklatura erabiliko da.
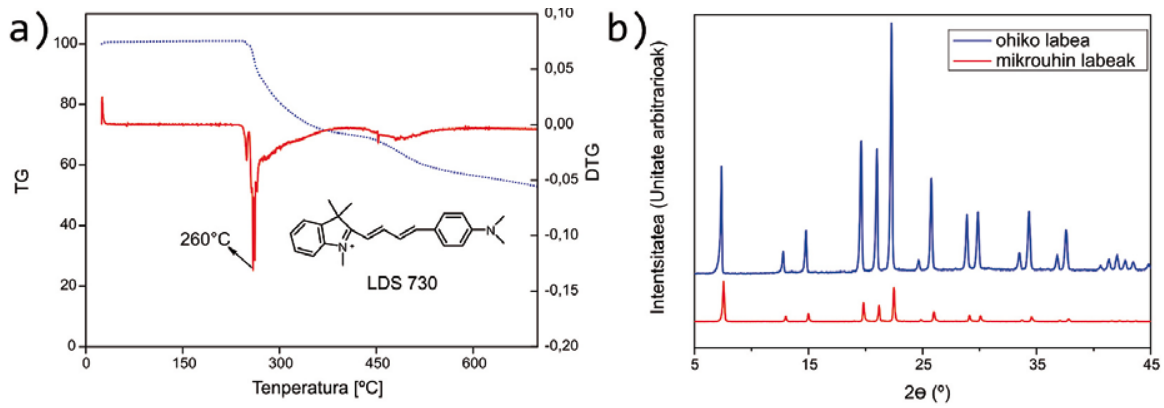

5. irudia. a) LDS 730 koloratzailearen masaren aldakuntza denboran zehar, tenperatura aldatuz (TG analisi termograbimetrikoa, urdina) eta deskonposizio tenperaturaren determinazioa aurreko analisiko kurbaren deribatua eginez (DTG). b) Sintetizatutako LDS730/AFI laginen (1. taulan adierazitakoak) X izpien difrakzioen irudiak.

Bi laginek pareko kolorea erakusten dute, urdin tonalitatekoa; beraz, koloratzaile kantitate antzekoa sartu dela bi kasuetan ondoriozta daiteke begi bistaz. Ekorketako mikroskopio elektronikoarekin eta mikroskopio optikoarekin ateratako argazkiek bi kristalizazio-morfologia erakusten dituzte. Ohiko labean sintetizatutako laginean (A lagina), egitura luzeak ikus daitezke, eraztun batez inguratuak eta forma hexagonalekoak $(\approx 40-60 \mu \mathrm{m}$ ingurukoak). Mikrouhinen bidez egindakoan (B lagina), ordea, 10-15 $\mu \mathrm{m}$ inguruko kristalak sortu direla ikusi da, zeinek zentroan prisma hexagonala eta ertzetan, aldiz, piramide hexagonalaren itxurako egitura erakusten baitute (ikus 6. irudia). Bi kasuetan behatutako forma hexagonal hori, MgAPO-5 aluminofosfatoari (AFI fasea) esleitzen zaio [16]. Tamainadistribuzioari dagokionez, B laginean uniformetasun handiagoa nabaritu da A laginarekin alderatuta; honetarako, $20 \mu \mathrm{m}$-ko tarteko distribuzioa lortu da.

Bestalde, aurretik azaldutako $\mathrm{X}$ izpien difrakzioen intentsitateak bat datoz mikroskopioan ikusitakoarekin. Hau da, mikrouhinen bidez lortutako B laginari esleitutako kristalinitate baxuagoak erlazio zuzena dauka kristalen tamainarekin. Izan ere, zenbat eta kristal-tamaina txikiagoa lortu, orduan eta gehiago murrizten da $\mathrm{X}$ izpien seinaleen intentsitatea. Hala ere, lagina osotasunean hartuz, bai tamaina eta bai morfologia homogeneoagoak 
ikus daitezke mikrouhin bidez lortutako laginean, beroketa mota horrek eskaintzen duen nukleazio azkarragoagatik. Hau da, mikrouhin-labearen sintesi-denbora laburra dela eta, nukleoak bizkorrago sortzen dira, eta horrek kristalen sorrera uniformeagoa eragiten du, sintesi-denboran tamaina desberdineko kristal asko sortzea saihestuz.

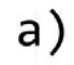

a)
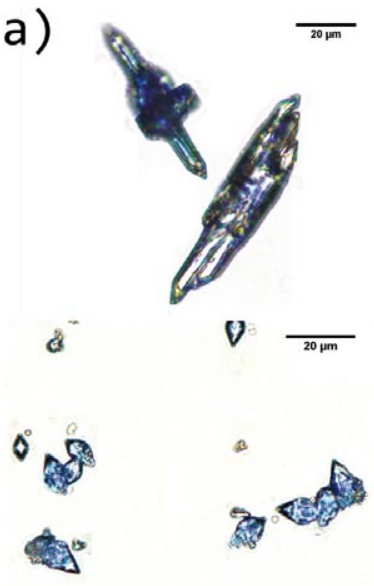
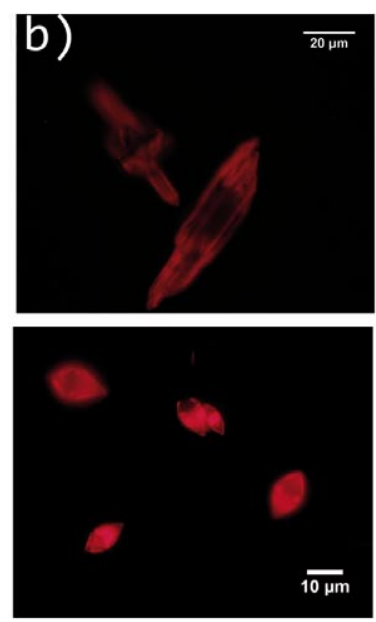
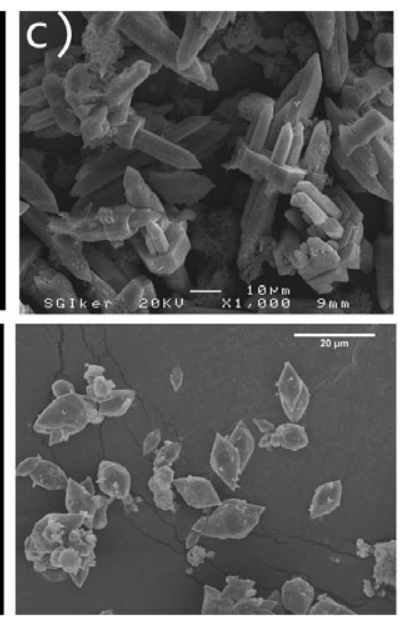

6. irudia. A (goian) eta B (behean) laginen a) mikroskopio optikoaren transmisioaren eta b) fluoreszentziaren irudiak, eta c) ekorketako mikroskopiko elektronikoaren irudia.

LDS 730/AFI material hibridoak 695-700 nm inguruan (1. taula) zentratuta dagoen oinarrizko xurgapen-banda (7b. irudia) eta sorbalda bat aurkezten ditu $600 \mathrm{~nm}$-ra. Xurgapen-banda hori, disoluzioan lortutakoarekin $\left(\lambda_{\text {xur: }}: 573 \mathrm{~nm} ; 7 \mathrm{a}\right.$. irudia) konparatuta, oso gorrirantz lerrokatuta dago. Banda nagusia eta horren sorbalda aztertzeko asmoz, izatez, B material hibridoarentzako xurgapen-bandaren dekonboluzioa egin da (7c. irudia); bi banda gaussiar lortu dira kurba azpitik, 3:1 azalerakoak. Lehenengoa, $604 \mathrm{~nm}$-an zentratutakoa, $\mathrm{S}_{1}$ lekuko kitzikapenari, edo berdina dena, xurgapenari, ezarri zaio. Hori da igorpen fluoreszentearen ohiko bide energetikoa: fluoroforoa argiztatzean, kitzikatu egiten da $S_{0}$ oinarrizko mailatik $S_{1}$ lehenengo maila kitzikatura, eta bertatik, erlaxatzean, argia igortzen du. Dekonboluzioan ikusten den bigarren banda $723 \mathrm{~nm}$-an kokatzen da, eta hori karga-transferentzia intramolekularrak sortutako egoera bati esleitzen zaio. Egoera horiek egitura molekularrean talde elektroi-emaileak eta elektroi-hartzaileak dituzten kromoforoetan agertu ohi dira, gurean kasu; molekularen karga osoaren banaketa aldatzen da. Dena den, normalean oinarrizko egoeran egonkorturik ez dauden egoerak izan ohi dira, eta, beraz, eskuarki ezin dira ikusi xurgapen-espektroan. Gure materialaren kasuan, 
ordea, karga-transferentzia intramolekularra oinarrizko egoeran egonkortzen dela ziurtatu da; horrek xurgapen-espektroan gorrirantz lerratutako banda bati bidea ematen dio. Egonkortze hori matrize ez-organikoak koloratzaileari ezarritako zurruntasunaren ondorio zuzena da, aldez aurretik frogatu den bezala [17].
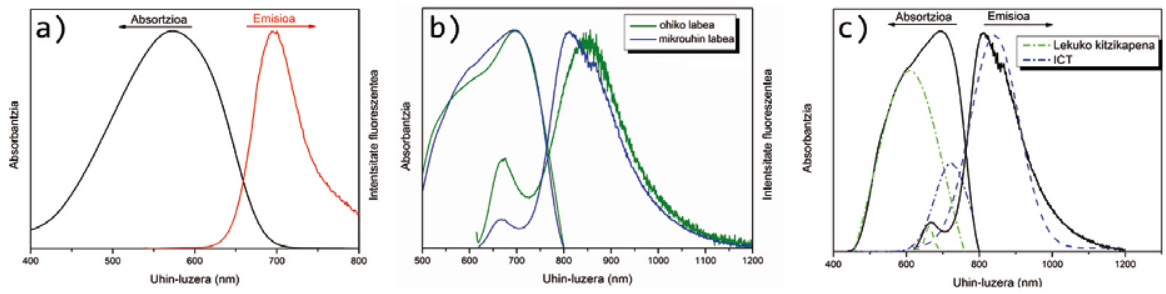

7. irudia. a) LDS 730-ren xurgapen (beltza) eta igorpen (gorria, $530 \mathrm{~nm}$-an kitzikatua) espektro normalizatuak ur-disoluzioan eta $\mathrm{pH}=7$ an neurtuta. b) LDS 730/AFI solidoen xurgapeneko eta igorpeneko (600 nm-an kitzikatuak) espektro normalizatuak. c) B laginaren xurgapen- eta igorpen-banda bakoitzaren dekonboluzioa, lekuko kitzikapenari eta karga-transferentzia intramolekularreko egoerari dagokiena.

Era honetan, hautsaren emisio-espektroak $660 \mathrm{~nm}$ inguruko indargabeko igorpen bat erakusten du $\mathrm{S}_{1}$ egoera elektronikotik, eta banda nagusi bat, karga-transferentziako egoerari egotzitakoa, infragorri hurbileko zonaldean: $847 \mathrm{~nm}$-an A laginerako, eta $814 \mathrm{~nm}$-an B laginerako (7c irudia). Berriro ere, lortutako emaitza fotofisiko hori aluminofosfatoak esleitutako zurruntasunaren ondorio zuzena da: espazioaren murrizketa bat lortzen da AFI ostalariaren nanokanaletan. Espazio-murrizketa horren ondorioz, halaber, ostalariak LDS 730aren konfigurazio laua induzitzen du. Konfigurazio hori karga-transferentziako egoeratik datorren igorpen fluoreszentearen erantzulea da, eta, adierazi denez, zurruntasuna ere inposatzen du: koloratzaile-molekulen errotazio eta bibrazio mugimenduak minimizatzen ditu, eta, honela, fluoreszentzia suspertzen. Izan ere, LDS 730 koloratzaileak $\%$ 1etik beherako etekin kuantiko fluoreszenteak ditu disoluzioan; gure materialetan \% 8ko etekinetara heltzen da.

Azpimarratzekoa da, atal honetan, infragorri hurbileko eremuan igortzen duen material baten etekin kuantiko fluoreszentearen hobekuntza. Horrelako bandak erakusten dituzten materialak oso interesgarriak dira biomedikuntzan, materialen zientzian eta horiekin erlazionaturiko arloe$\tan$ [18-21]. Bereziki, bioirudigintzarako 700 eta $1.000 \mathrm{~nm}$ bitartean igortzen duten materialak dira erakargarriak, uhin-luzeren tarte horretan organismoetatik eta ehunetatik datozen interferentziak minimizatzen direlako, eta baita argiaren sartze-sakonera hobetzen delako ere (2-3 cm-ko barneratzea lor daiteke 675-800 nm-ko leihoan) [22]. Izan ere, infragorri hurbi- 
leko eremuan ehun biologikoen argia xurgatzeko gaitasuna asko murrizten da.

Beraz, ezaugarri fotofisikoen hobekuntza arrakasta handiarekin lortu da ohiko labea zein mikrouhinak erabiliz. Hori honela izanik, mikrouhinen emaitza arrakastatsuak azpimarratu behar dira: propietate fotofisiko berberak dituen material hibrido bat lortzen da, denboraren magnitude-ordena bat murrizten da ( 24 ordutik 2 ordura), eta tamaina distribuzio hobea eta homogeneoagoa lortzen da. [23] Abantaila horiek joko handia ematen dute dopatutako material hibridoetan; koloratzaileak, molekula organikoak izanik, ezegonkorrak izan ohi direlako sintesi hidrotermaletako baldintzetan. Beraz, ohiko labean deskonposatzen diren koloratzaile horiek, mikrouhinlabeak aplikatuz, material hibridoen poroetan txertatuko dira, zorionez degradaziorik jasan gabe [24].

\section{ONDORIOAK}

LDS 730 koloratzailea MgAPO-5 aluminofosfatoaren kanalen barnean erantsi da, mikrouhin-labea zein labe konbentzionala erabiliz (koloratzailearen dimentsioaren antzeko tamainakoak dira kanalak). Lortutako emaitza esperimentalak aztertuz, frogatu da mikrouhinen teknikak, orokorrean, punta-puntako tresna gisa jotzen duela material mesoporotsuak (2 eta $50 \mathrm{~nm}$ tarteko poroak dituztenak) eta mikroporotsuak ( $2 \mathrm{~nm}$-tik beherako poroak dituztenak) sintetizatzeko; material horiek metodo sinple eta bizkor ( 2 ordukoa) baten bidez sortzen dira. Bestalde, hainbat abantaila eskaintzen ditu, hala nola nukleazio homogeneoa (hazkunde kristalinoaren hasiera), kristalizazio azkarragoa, berehalako sintesiak eta kristal txikien eta uniformeen lorpena. Uniformetasun hori nukleazio homogeneoarekin zuzenki lotuta dago; izan ere, sintesia labean gertatzen den kasuetan, nukleazio motelaren eraginez, kristalak denbora desberdinetan zehar hazten dira; horrek tamaina askotako kristalei bidea ematen die. Hori dela eta, mikrouhinekin, partikulen tamaina distribuzio estuagoa lortzen da labearekin baino. Onura horiek aniztasun eta aukera askoko material hibridoak sortzea ahalbidetzen dute: koloratzaileen degradazioa eragozten da, eta, honela, material optikoen aukerak asko zabaltzen dira.

Honetaz gain, sintetizatutako material hibridoa sortzen duten unitate organiko eta ez-organikoen arrazoizko aukeraketa eta diseinua direla bide, infragorri hurbileko eremuan banda espektralak erakusten dituen sistema lortu da, propietate fotofisiko hobetuak azaltzen dituena koloratzaile hutsarekin konparatuz. Egiaztatu da, beraz, material erakargarriak lor daitezkeela koloratzaile organikoak matrize ez-organiko egokietan kapsulatzean; bada, ezaugarri bereziak eskatzen dituzten arlo edo aplikazio espezifikoetarako balio dute. 


\section{ESKER ONAK}

Artikulu honek Eusko Jaurlaritzaren (IT912-16) eta Espainiako MINECO (MAT 2017-83856-C3-3-P) ikerketa-proiektuen dirulaguntza izan du, eta ikerketa UPV/EHUk finantzatutako doktorego aurreko beka bati esker gauzatu ahal izan da. Halaber, SGIkerrek X izpien difrakzioetarako eta ekorketako mikroskopio elektronikoko argazkietarako emandako laguntza asko eskertzen da.

\section{BIBLIOGRAFIA}

[1] L. NICOLE, C. LABERTY-ROBERT, L. ROZES, eta C. SANCHEZ, 2014. «Hybrid materials science: A promised land for the integrative design of multifunctional materials» Nanoscale, 6, 6267-6292 .

[2] G. KICKELBICK, 2007. Hybrid Materials: Synthesis, Characterization, and Applications. Wiley-VCH VerlagGmbH\&Co., Weinhem.

[3] C. ROTTMAN, M. OTTOLENGHI, R. ZUSMAN, O. LEV, M. SMITH, G. GONG, M. L. KAGAN, D. AVNIR, 1992. «Doped sol-gel glasses as pH sensors» Mater. Lett., 13, 293-298.

[4] L. SHAPIRO eta D. AVNIR, 2013. «Multiple One-Pot Reaction Steps using Organically Doped Metallic Hybrid Catalyst» ChemCatChem, 5, 2195-2198.

[5] C. SANCHEZ, B. LEBEAU, F. CHAPUT, eta J. P. BOILOT, 2003. «Optical properties of functional hybrid organic-inorganic nanocomposites» $A d v$. Mater., 15, 1969-1994.

[6] S. PAROLA, B. JULIÁN-LÓPEZ, L. D. CARLOS, eta C. SANCHEZ, «Optical Properties of Hybrid Organic-Inorganic Materials and their Applications» 2016. Adv. Funct. Mater., 26, 6506-6544.

[7] R. GARCÍA, V. MARTÍNEZ-MARTÍNEZ, R. SOLA-LLANO, I. LÓPEZ-ARBELOA, eta J. PÉREZ-PARIENTE, 2013. «One-dimensional antenna systems by crystallization inclusion of dyes (One-Pot Synthesis) within zeolitic MgAPO-36 nanochannels» J. Phys. Chem. C, 117, 24063-24070.

[8] E.G. DEROUANE, F.LEMOS, C. NACCACHE, F. R. RIBEIRO. 1991. Zeolite Microporous Solids: Synthesis and Reactivity, Springer, Portugal.

[9] V. MARTÍNEZ-MARTÍNEZ, R. GARCÍA, L. GÓMEZ-HORTIGÜELA, R. SOLA-LLANO, J. PÉREZ-PARIENTE, eta I. LÓPEZ-ARBELOA, 2014. «Highly Luminescent and Optically Switchable Hybrid Material by OnePot Encapsulation of Dyes into MgAPO-11 Unidirectional Nanopores» ACS Photonics, 1, 205-211.

[10] L. CERDÁN, A. COSTELA, I. GARCÍA-MORENO, J. BAÑUELOS, I. ELÓPEZ-ARBELOA, 2012. «Singular laser behavior of hemicyanine dyes: unsurpassed efficiency and finely structured spectrum in the near-IR region» Laser Phys. Lett., 9, 426. 
[11] J. M. BENNETT, J. P. COHEN, E. M. FLANIGEN, J. J PLUTH eta J. V. SMITH, 1983. «Crystal-Structure of Tetrapropylammonium Hydroxide-Aluminum Phosphate Number-5» ACS Symp. Ser., 218, 109-118.

[12] G. A. TOMPSETT, W. C. CONNER, eta K. S. YNGVESSON, 2006. «Microwave synthesis of nanoporous materials» ChemPhysChem, 7, 296-319.

[13] Y. CAO, H. J. WEI, eta Z. N. XIA, 2009. «Advances in microwave assisted synthesis of ordered mesoporous materials» Trans. Nonferrous Met. Soc. China, 19, s656-s664.

[14] A. OLIDEN-SÁNCHEZ, R. SOLA-LLANO, I. LÓPEZ-ARBELOA, eta V. MARTÍNEZ-MARTÍNEZ, 2018. «Enhancement of NIR emission by a tight confinement of a hemicyanine dye within zeolitic MgAPO-5 nanochannels» Photochem. Photobiol. Sci., 17, 917-922.

[15] J. M. BENNETT, J. P. COHEN, E. M. FLANIGEN, J. J. PLUTH, eta J. V. SMITH, 2009. «Crystal Structure of Tetrapropylammonium Hydroxide-Aluminum Phosphate Number 5» Intrazeolite Chemistry, 6, 109-118.

[16] L. LI, Y. WU, eta S.-C. RUAN, 2008. «Investigations of a new hexagonal micro-lasers based on AlPO-5 crystal» Journal Shenzhen Univ. Sci. Eng., 25, 158-162.

[17] R.SOLA-LLANO, V.MARTÍNEZ-MARTÍNEZ, Y.FUJITA, L.GÓMEZHORTIGÜELA, A.ALFAYATE, H.UJI-I, E.FRON, J.PÉREZ-PARIENTE eta I.LÓPEZ-ARBELOA, 2016. «Formation of a Nonlinear Optical HostGuest Hybrid Material by Tight Confinement of LDS 722 into Aluminophosphate 1D Nanochannels» Chem. - A Eur. J., 22, 15700-15711.

[18] J. O. ESCOBEDO, O. RUSIN, S. LIM, eta R. M. STRONGIN, 2010. «NIR dyes for bioimaging applications» Curr. Opin. Chem. Biol., 14, 64-70.

[19] F. LYNG, E. GAZI, eta P. GARDNER, 2011. Biomedical Applications of Synchrotron Infrared Microspectroscopy, The Royal Society of Chemistry.

[20] C. CHEN eta W. HAIFANG, 2016. Biomedical Applications and Toxicology of Carbon Nanomaterials, Wiley.

[21] D. I. ELLIS eta R. GOODACRE, 2006. «Metabolic fingerprinting in disease diagnosis: biomedical applications of infrared and Raman spectroscopy» Analyst, 131, 875-885.

[22] M. C. DEROSA eta R. J. CRUTCHLEY, 2002. «Photosensitized singlet oxygen and its applications» Coord. Chem. Rev., 233-234, 351-371.

[23] V. VALENTIN, S. MINTOVA, eta M. TSAPATSIS, 2009. Ordered Porous Solids - Recent Advances and Prospects., Elsevier Science.

[24] F. LAERI, F.SCHÜTH, U.SIMON, M.WARK, 2013. Host-Guest-Systems Based on Nanoporous Crystals. Wiley-VCH Verlag GmbH \& Co. 